Chapter 7

\title{
Renal Transporters and Biomarkers in Safety Assessment
}

\author{
P.D. Ward, D. La and J.E. McDuffie \\ Additional information is available at the end of the chapter \\ http://dx.doi.org/10.5772/54857
}

\section{Introduction}

Understanding the effect of renal transporters on the distribution of drugs, metabolites, and endogenous compounds (e.g., biomarkers for renal toxicity and physiological regulators) are important in safety assessment studies [1]. Drugs (and their metabolites) that preferentially distribute into the kidney may have a greater potential to induce renal toxicity because these compounds may accumulate in the cells surrounding/forming the renal tubules. This disposition may not be deduced by simply sampling plasma; therefore, sampling kidney tissue in addition to plasma is important for measuring concentrations of drugs when renal toxicity is observed in animals. In human safety assessment, sampling of kidney is not generally feasible; therefore, the utility of qualified tissue-, serum- and/or urine-specific biomarkers may help to extrapolate between animal tissue and human exposures.

This chapter will review the role of renal transporters and biomarkers in the safety assessment of drug candidates. Membrane permeability and types of drug transporters will be introduced with focus on specific renal transporters. Examples of cause-effect relationships between renal transporters and toxicity will be discussed. The effect of drugs on the ability of renal transporters to regulate the disposition of endogenous compounds involved in maintaining homeostasis will be discussed. In addition, a case example on the effect of a proprietary drug candidate on a classical biomarker of renal safety will be highlighted where an increase of this biomarker via inhibition of a renal transporter was determined to be benign and not the consequence of renal toxicity. Finally, we will highlight the recent qualification of novel diagnostic renal urinary biomarkers that outperform the traditional renal biomarkers, serum creatinine $(\mathrm{sCr})$ and/or blood urea nitrogen (BUN) in monitoring renal injury in preclinical (rat) studies. We will also highlight use of selected novel renal biomarkers in rat and dog studies with the paradigm renal toxicant, cisplatin. 


\section{Transport through cellular barriers}

Molecules cross cellular barriers by three main pathways: (1) passive diffusion across the cell membranes; (2) passive diffusion between adjacent cells; and (3) carrier-mediated transport (Fig. 1). Lipophilic molecules cross the cells membrane by transcellular diffusion. By contrast, hydrophilic molecules that are not recognized by a carrier cannot partition into the hydrophobic membrane and thus traverse the epithelial barrier via the paracellular pathway. Hormones and certain immune system molecules can utilize membrane invaginations for transport across the cell (e.g. via caveolae). All other compounds must interact with carrier proteins, either in a facilitated manner (down the concentration gradient) or via "active" transport, potentially against a concentration gradient. The driving force to allow active transport may include the use of ATP hydrolysis, $\mathrm{pH}$ gradients, or electrogenic properties of the cell. [2]

Transporters depicted in Pathway (4) (Fig. 1) efflux compounds from cell into the lumen or blood and are thought to act as a cellular defender to prevent xenobiotics from either entering the cells or endogenous waste products from accumulating in the cells. These types of transporters are referred to as efflux transporters. With respect to pharmaceutical compounds, clinically relevant transporters are members of the ATP-binding cassette (ABC) superfamily membrane bound transporters [3]. P-glycoprotein (P-gp) is the most well characterized ABC transporter $[4,5]$. Other efflux transporters such as multidrug resistance-associated protein (MRP) members in proximal tubular cells function as an extrusion pump for organic anions from the apical membrane, especially large and hydrophobic organic anions such as glutathione and glucuronide conjugates [6].

Transporters depicted in Pathway (3) (Fig. 1) facilitate transport of nutrients (e.g., amino acids and glucose) and drugs into cells. These types of transporters are referred to as uptake or influx transporters. For nutrients, uptake transporters are essential for reabsorbing glucose from the tubule lumen into the systemic circulation. The importance of these types of transporters and the impact of interrupting their function on safety assessment will be further discussed in Section 5 .

For pharmaceutical compounds, members of the Solute Carrier (SLC) superfamily of membrane transport proteins (depicted in Pathway (5), transport an extraordinarily diverse set of solutes, including both charged and uncharged organic molecules as well as inorganic ions) have wide implications on human physiology, pathology, and in multiple therapeutic areas [7]. Examples of SLC transporters (Fig. 2) include organic cation transporters (OCT) and organic anion transporters (OAT). Renal transporters (e.g., OAT and OCT) allow the entry of drugs (with low passive transcellular permeability) through the basolateral membrane into the tubule cells, which leads to elimination of the drug into urine by transport of the drug through the apical membrane by either SLC or efflux transporters (i.e., tubular secretion). Interestingly, SLC transporters expressed on the apical or luminal membrane (e.g., novel organic cation transporters (OCTN) and OAT4) may also play a role in tubular reabsorption, process by which compounds are removed from the tubular fluid and transported into the blood [8]. 

(1)
(2)
(3)
(4)
(5)
(6)

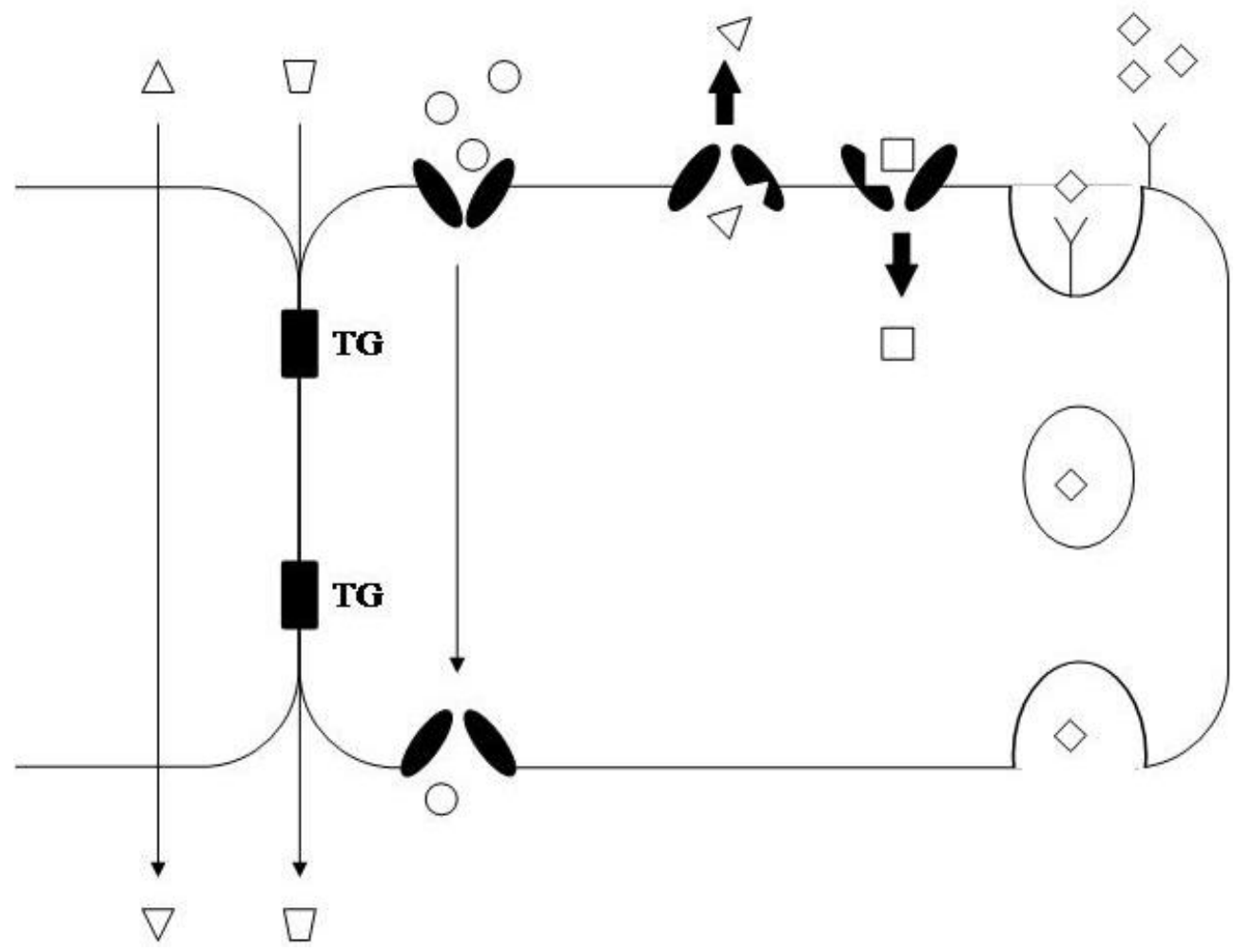

Figure 1. Routes of translocation through cellular barriers. (1) Lipid soluble compounds can permeate through the epithelium by simple passive diffusion (transcellular route). (2) Small molecular weight compounds such as $\mathrm{CO}_{2}$ can permeate through the tight junctions (TG) between cells (paracellular route). (3)Facilitative transport (e.g., uptake of amino acids) occurs via a transport carrier down the concentration gradient of the solute. (4)Transport can also occur via a carrier, but against the concentration gradient of the solute. In the case of efflux transporters such as P-glycoprotein (P-gp), ATP-hydrolysis is the driving force for this transport. (5) Uptake carriers such as the organic anion or organic cation transporters can also transport substances against a concentration gradient. The driving force is dependent on the particular transporter but can be $\mathrm{pH}$-dependent or electrogenic. (6)Some hormones are transported through the epithelium via receptor-mediated transcytosis. The ligand binds to a cell surface receptor, which cause an invagination in the membrane. This invagination is internalized and carried to the opposite membrane where the ligand is then released ([2]; reproduced with permission).

\section{Drug transporters in the kidney}

The kidney is responsible for clearance of many drugs including polar hydrophilic compounds such as ß-lactam antibiotics and non-steroidal anti-inflammatory drugs [9]. Polar compounds may be actively taken up by the proximal tubule cells through a variety of transporters 
including OCT2, OAT1 and 3 (Fig. 2, Table 1). Once taken up into the proximal tubule cells, compounds generally must efflux out of the cells into the urine by a different set of transporters including MRP2, P-gp, and MRP4 (i.e., facilitation of tubular secretion). In the human kidney, the order of transporter mRNA expression (highest to lowest) is OAT1, OAT3, P-gp, MRP2, and OCT2 [10].

Recently, the importance of renal transporters called multidrug and toxin extrusion proteins (MATE), which are expressed in the apical (luminal) membrane of proximal tubule epithelial cells, have been highlighted [11]. Functionally, MATEs act as efflux transporters, thereby mediating the excretion of metabolic waste products and xenobiotics. Two isoforms, MATE1 and 2, have been identified, and, so far, only a limited number of substrates, including clinically used drugs such as metformin and cimetidine, are known [12].

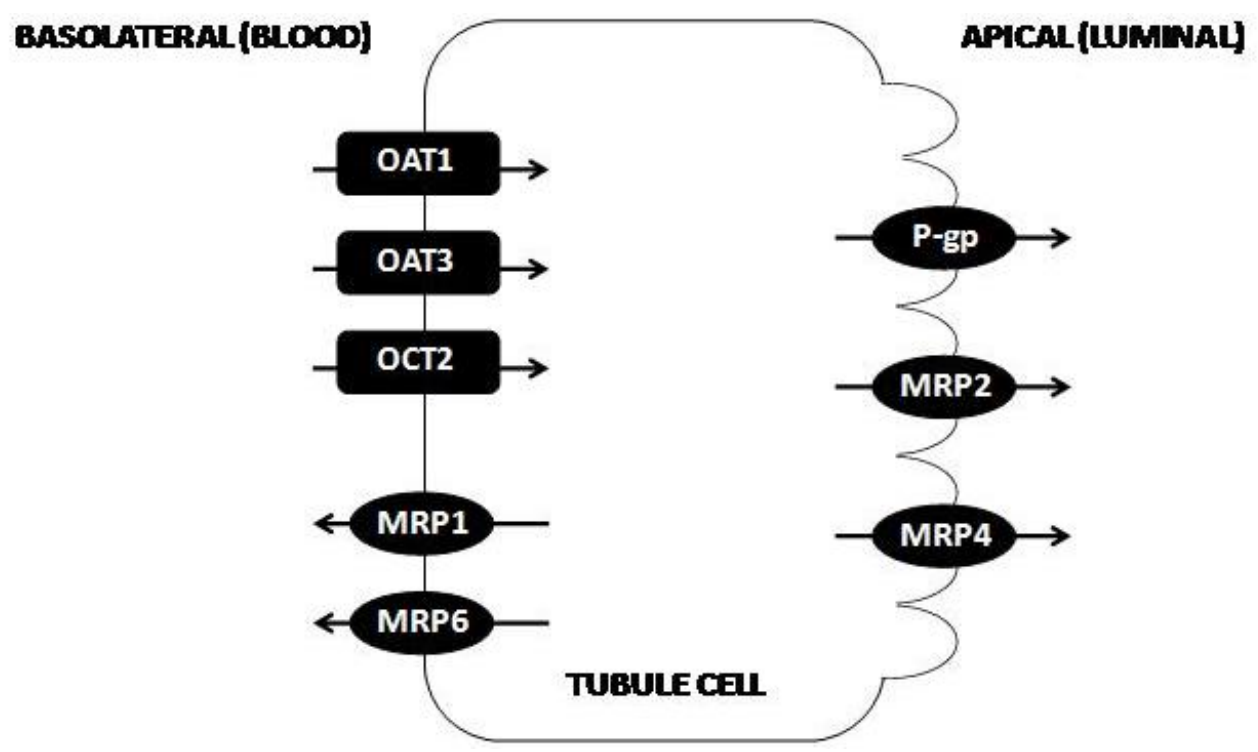

Figure 2. Select drug transporters located in the kidney predicted to play a role in drug distribution and elimination. Influx transporters located on the basolateral or blood side of the kidney tubule cells include the organic anion transporters OAT1 and 3, and the organic cation transporter OCT2. Efflux transporters located on the basolateral side include multiple members of the multidrug resistance protein family such as MRP1 and MRP6. Efflux transporters located on the apical or luminal side of the tubule membrane which pump drugs from the interior of the tubule cell into the tubular fluid include P-gp, MRP2 and MRP4 ([2]; reproduced with permission).

Compounds may be reabsorbed from the tubular fluid back into the tubule cells or cleared from the body. The interplay between various transporters located on the basolateral (blood) or apical (luminal) side dictates the overall renal clearance of a compound. As with the liver, renal transporters can therefore be a site of potential drug-drug interactions (DDI). Inhibition of the basolateral transporters (by the primary compound, metabolites, or a co-administered compound) can lead to increased exposure of the drug and longer half-lives in the 
systemic circulation. Inhibition of renal uptake of some drugs may actually induce toxicity by inhibiting their renal excretion. For example, severe methotrexate toxicity due to an increase in serum concentrations was observed in patients after co-administration with probenecid which inhibited OAT1 and MRP, and consequently the tubular secretion of methotrexate $[13,14]$. Inhibition of the luminal efflux transporters, again by either the compound itself or a co-administered drug, can also cause an increase in systemic exposure if the basolateral transporters are able to transport the compound back into the systemic circulation. Alternatively, inhibition of the luminal efflux transporters can cause a compound to be "trapped" in the cell which may lead to renal toxicity [2].

\begin{tabular}{|c|c|c|c|}
\hline Protein/Gene & Substrates & Inhibitors & References \\
\hline OCT2/SLC22A2 & $\begin{array}{l}\text { cimetidine, metformin, MPP+, } \\
\text { quinine TEA }\end{array}$ & $\begin{array}{l}\text { cimetidine, clonidine, procainamide, } \\
\text { quinine }\end{array}$ & {$[15,16]$} \\
\hline OAT1/SLC22A6 & $\begin{array}{l}\text { adefovir, } \\
\text { para-aminohippurate, furosemide }\end{array}$ & $\begin{array}{l}\text { furosemide, indomethacin, } \\
\text { probenecid, urate }\end{array}$ & {$[17,18]$} \\
\hline OAT3/SLC22A8 & $\begin{array}{l}\text { benzylpenicillin, furosemide, } \\
\text { methotrexate, pravastatin }\end{array}$ & $\begin{array}{l}\text { gemfibrozil, indomethacin, } \\
\text { probenecid, salicylate }\end{array}$ & {$[17,19]$} \\
\hline P-gp/ABCB1 & $\begin{array}{l}\text { digoxin, daunorubicin, doxorubicin, } \\
\text { fexofenadine, irinotecan, paclitaxel, } \\
\text { quinidine, saquinavir, verapamil }\end{array}$ & $\begin{array}{l}\text { cyclosporine A, elacridar, quinidine, } \\
\text { valspodar, verapamil }\end{array}$ & {$[4,5,20,21]$} \\
\hline MRP1/ABCC1 & $\begin{array}{l}\text { daunorubicin, etoposide, } \\
\text { methotrexate, glutathione, } \\
\text { glucuronide and sulfate conjugates, } \\
\text { vincristine }\end{array}$ & $\begin{array}{l}\text { delavirdine, efavirenz, MK571, } \\
\text { probenecid }\end{array}$ & {$[6,20]$} \\
\hline MRP2/ABCC2 & $\begin{array}{l}\text { Similar to MRP1, cisplatin, } \\
\text { methotrexate }\end{array}$ & $\begin{array}{l}\text { delavirdine, efavirenz, MK571, } \\
\text { probenecid }\end{array}$ & {$[20,22,23]$} \\
\hline MRP4/ABCC4 & $\begin{array}{l}\text { adefovir, azidothymidine } \\
\text { monophosphate, prostaglandins, } \\
\text { methotrexate }\end{array}$ & indomethacin, ketoprofen & {$[24,25]$} \\
\hline
\end{tabular}

Table 1. Substrates and inhibitors of select renal transporters ([2]; partially reproduced with permission)

\section{Importance of plasma sampling and understanding drug disposition in renal tissue during safety assessment}

Compound-induced toxicities can be better extrapolated from animals to humans when these comparisons are based on toxicokinetics instead of dose alone [26]. For example, the safety margin that is based on the ratio of the animal exposure at the no observed adverse effect level (NOAEL) to human exposure at the efficacious dose is a key predictor of human safety risk. To calculate this safety margin, the animal and human exposure is determined by analyzing 
drug and metabolite(s) concentrations in plasma, which is the most practical and widely accepted way of assessing this risk. However, most safety issues are not due to drug plasma concentration but due to concentration of drug in various organs/tissues.

Sampling plasma and extrapolating this exposure to organs or tissues assumes that 1) concentration of drug in plasma is in equilibrium with concentrations in tissues, 2) changes in plasma drug concentrations reflect changes in tissue drug concentrations over time, and 3) distribution of drug and its metabolites are not affected by cells (e.g., drug transporters and enzymes) that protect many of these tissues [27]. Drug transport into tissues may not be a passive process and may depend on drug transporters, and thus these assumptions may result in an inaccurate assessment of target organ exposure to drug and/or metabolites. Even without a drug being a substrate for a drug transporter, lysosomal trapping of weak bases (e.g., liver and lung) or accumulation in membranes (e.g., muscle) can occur that can subsequently give rise to preferential distribution of the drug and its metabolites. For more details, refer to http:// www.intechopen.com/books/toxicity-and-drug-testing/toxicokinetics-and-organ-specifictoxicity [27].

If the compound enters tubular cells via uptake transporters (e.g. OCT2, OAT1, OAT3), but not effluxed (into luminal fluid or urine), very high compound concentrations can occur in the renal cells/tissue. A convincing cause-effect relationship exists between uptake of renal toxicants via transporters and associated renal toxicity where co-administration of probenecid (inhibits renal uptake of organic anions) or either cimetidine or imatinib (inhibits renal uptake of organic cations) may reduce renal toxicity (by limiting uptake). For example, co-administration of cisplatin with imatinib prevents cisplatin-induced renal toxicity by inhibiting influx via OCT2 [28]. Another example is co-administration of cephaloridine with probenecid lowers the potential risk of cephaloridine-induced renal toxicity by inhibiting the OAT1-mediated transport of cephaloridine into the proximal tubule cell [29].

Influx transporter OAT1 (minor contribution by OAT3) is involved in the renal safety of acyclic nucleotide phosphonates (adefovir, cidofovir, and tenofovir), which are eliminated predominantly into the urine [30-32]. The dose-limiting toxicity for acyclic nucleotide phosphonates is renal failure, particularly for adefovir and cidofovir which may accumulate in the kidney [33,34]. Patients treated with tenofovir exhibit a lower incidence of renal dysfunction at doses used to treat HIV compared to adefovir and cidofovir [35, 36]. In vitro studies showed that cells expressing human OAT1 showed enhanced toxicity to adefovir and cidofovir [500-fold) compared to cells that do not express OAT1 [37]. Unlike adefovir and cidofovir, tenofovir is less nephrotoxic to OAT1-expressing cells [38]. Additional in vitro studies demonstrated that OAT1 inhibitors such as nonsteroidal anti-inflammatory drugs, protect OAT1-expressing cells from adefovir- and cidofovir-induced cytotoxicity by preventing their cellular accumulation [39].

Efflux transporters in the kidney also play a potential role in the safety of a drug by pumping the drug out of the tubule cell and into the blood or urine (tubular fluid) and preventing the accumulation of the drug in the tubule cell. For example, the efflux transporters, MRPs, may be another crucial factor in the renal accumulation of acyclic nucleotide analogs (in addition to the uptake) and subsequent nephrotoxicity. Interestingly, renal toxicity in patients is 
observed with tenofovir when co-administered with an inhibitor of MRP2, ritonavir [40]. However, tenofovir is also a substrate for MRP4 that may not be inhibited by ritonavir [41, 42]. Other members of the MRP family (MRP5 and 8) may also be involved in the transport of acyclic nucleotide analogs [43]. Transport of adefovir and cidofovir was not observed in the membrane vesicles expressing human MRP2 and BCRP; furthermore, transport of adefovir and tenofovir but not cidofovir was observed only in the membrane vesicles expressing MRP4 [41]. To support these in vitro observations, the kidney accumulation of adefovir and tenofovir was significantly greater in Mrp4 knockout mice; however, there was no change in the kinetic parameters of cidofovir in these mice [41].

Another example of the relationship between efflux transporters and renal safety is MATE and platinum drugs. MATE can effectively mediate the transport of oxaliplatin, but not that of cisplatin [44]. Interestingly, oxaliplatin is effectively transported into renal proximal tubular cells by OCT2 but does not accumulate due to MATE-mediated renal extrusion, which may be the reason that oxaliplatin is much less nephrotoxic than cisplatin. Therefore, the interplay between renal OCTs and MATEs may influence the pharmacokinetics of platinum compounds and may critically determine the severity of platinum-associated adverse events [45].

This idea of reducing tubule exposure or even renal tissue half-life and consequently increasing the safety of drugs is also emphasized by studies investigating differences in renal safety of bisphophonates. In a rat model, zoledronic acid, but not ibandronate, induces progressive renal toxicity [46]. Ibandronate has a terminal renal tissue half-life of 24 days [47], whereas the renal tissue half-life of zoledronic acid (150-200 days) does not allow enough time for repair of renal damage [48]. Renal excretion is the only route of elimination of bisphosphonates. Interestingly, studies in rats demonstrated that alendronate is actively secreted by an uncharacterized renal transport system, and not by the anionic or cationic renal transport systems [49].

Understanding the tissue distribution and the substrate specificity for drug transporters can significantly aid safety assessment. In addition, this increased understanding can support the development of drugs with improved safety $[1,27]$ and/or a different route of administration that avoids distribution to the organ(s) where the compound-induced toxicity occurs. For example, an aerosolized form of $\left[{ }^{14} \mathrm{C}\right]$-cidofovir (dose-limiting toxicity is nephrotoxicity) administered to mice (via inhalation) results in the prolonged retention of radiolabeled drug in the lungs (site of initial viral replication) at levels exceeding those in the kidneys [34]. In contrast, subcutaneous injection produces much higher concentrations of $\left[{ }^{14} \mathrm{C}\right]$-cidofovir in the kidneys compared to the lungs [34]. Possibly in the future, the disposition of drug candidates may be directed by targeting specific drug transporters in organs like the kidney to significantly improve the renal safety of the drug candidate.

\section{Importance of renal transporters in the regulation of homeostasis}

Renal transporters regulate disposition of endogenous compounds that control homeostasis of a physiological system. Therefore, alteration in the activity of renal transporters by drugs may be a method to treat disease but also unexpected changes to the activity of these trans- 
porters may induce adverse effects. For example, Na+-dependent dicarboxylate transporters and OATs are involved in the disposition of dicarboxylates which are important regulators of the renovascular system; therefore, these renal transporters may play an important role in the maintenance of blood pressure [50]. Another example is the role of renal transporters in the regulation of serum uric acid levels where renal transporters of uric acid like GLUT9 (SLC2A9) may be a target for treatment of gout [51].

Recently, renal glucose transport has become a very active target for drug development. The kidney reabsorbs $99 \%$ of the glucose that filters through the renal glomeruli [52]. Approximately $90 \%$ of the glucose is reabsorbed by the low affinity, high capacity sodium-dependent glucose cotransporter (SGLT) 2 in the proximal tubules. The remaining glucose is reabsorbed by the high affinity, low capacity transporter, SGLT1 (expressed in the segment 3 of the proximal tubule). Co-transport with sodium enables movement of glucose by SGLTs against a concentration gradient, with the sodium gradient maintained by the $\mathrm{Na}+\mathrm{K}+\mathrm{ATPase}$ pump. Individuals with SGLT2 mutations (e.g., familial renal glucosuria or FRG) have persistent yet benign renal glucosuria [53]. Similar to the effect observed with FRG, novel drugs are being developed to reduce glucose reabsorption by inhibiting SGLT2. One such example, dapagliflozin is a selective SGLT2 inhibitor that is being developed for the treatment of type 2 diabetes mellitus, a disorder characterized by elevated blood glucose [54]. In diabetic rat models, dapagliflozin has been shown to decrease serum glucose concomitant with glycosuria. Similar effects have been observed in clinical trials with decreased hemoglobin A1c, fasting plasma glucose, postprandial glucose, and body weight in patients with type 2 diabetes.

\section{Importance of renal drug transporters in the disposition of a classical biomarker in renal safety assessment}

Creatinine is a breakdown product of creatine phosphate in muscle that is cleared by glomerular filtration and tubular secretion, and is routinely used as a diagnostic biomarker of renal function. For example, $\mathrm{sCr}$ can be used to estimate creatinine clearance which is then used to calculate glomerular filtration rate (GFR). Generally, a doubling of sCr suggests a $50 \%$ reduction in GFR.

Yet, sCr measurement as an indicator of compound-induced renal toxicity is often unreliable as $\mathrm{sCr}$ levels can be altered by changes in the levels of muscle mass and/or dietary protein. For example, sCr levels are often less reliable for detecting impaired GFR in the elderly, females, those with chronic illness associated with muscle wasting, African Americans, amputees, and vegans; various equations can be used to adjust for some of these factors to obtain a more reliable estimation of GFR [55, 56].

Creatinine is actively secreted by organic cation transporters including OCT2 and MATE which results in an overestimation of GFR by up to $40 \%$ [57-60]. For example, a drug that inhibits OCT2 can cause an increase in sCr levels independent of renal impairment [61]. Increased sCr levels in such cases typically stabilize over time and are not considered clinically relevant. 
$\mathrm{sCr}$ increases due to OCT2 and MATE inhibition show a characteristic temporal pattern. When a drug is administered over several days, creatinine levels increase quickly, reach a plateau, and return to baseline levels shortly after drug discontinuation. This pattern is illustrated in the following case example from a clinical study with Compound A (Fig. 3). Subjects were administered placebo or one of three dose levels of Compound A daily for 2 weeks. sCr levels were unchanged for the placebo group, but mild, dose-dependent increases were observed for subjects receiving Compound A. Increases were observed at the first post-treatment time point, and increased levels were maintained during the 2-week treatment period. sCr levels decreased once treatment was discontinued. In nonclinical studies (rat and monkey) with Compound $\mathrm{A}$, there was no evidence of renal injury associated with $\mathrm{sCr}$ increases even when elevated sCr levels were maintained for durations as long as 9 months. The time course and magnitude of the $\mathrm{s} \mathrm{Cr}$ changes observed with Compound A are consistent with transporter inhibition and have been observed for marketed drugs, such as cimetidine and trimethoprim. For cimetidine, maximum inhibition of $\mathrm{sCr}$ secretion occurs within 24 hours after administration and $\mathrm{sCr}$ levels return to baseline several days after discontinuation of dosing [62].

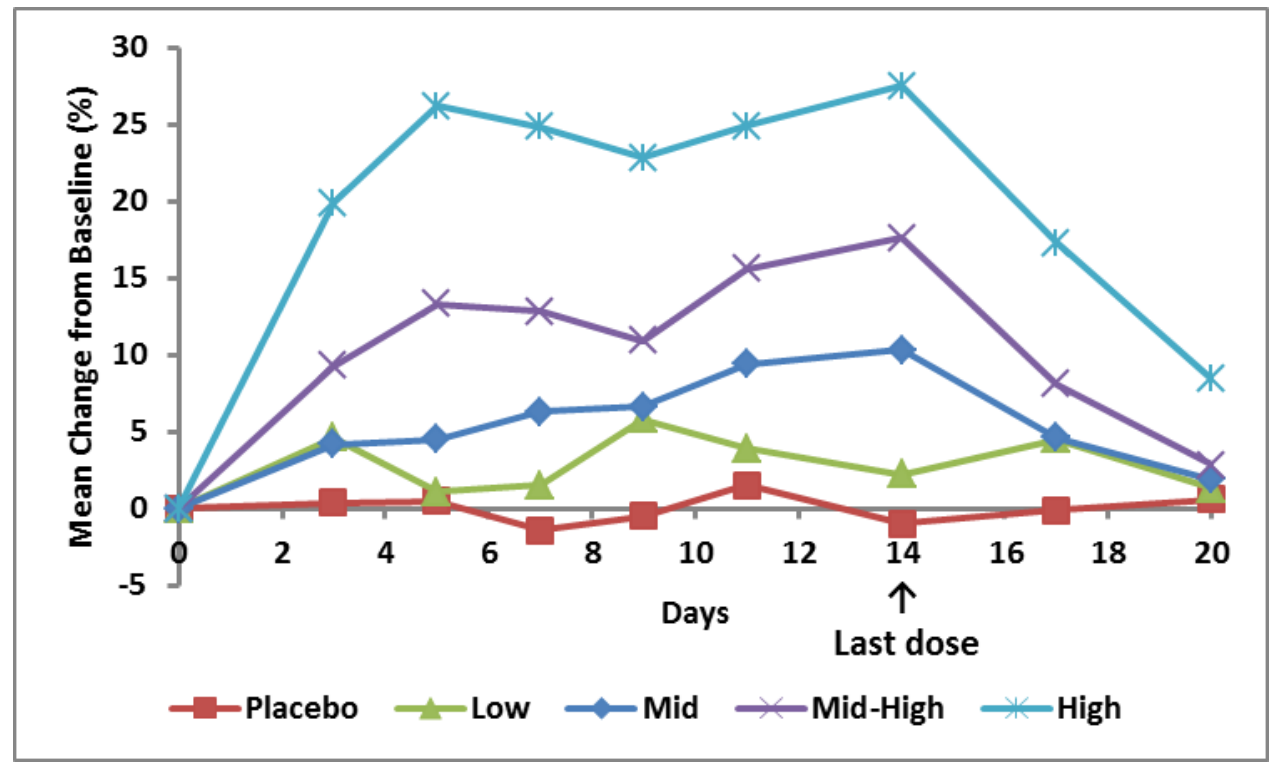

Figure 3. Temporal pattern of $\mathrm{s} C r$ changes in human subjects following 14 days oral administration of Compound $\mathrm{A}$.

A proposed strategy for investigating increased $\mathrm{sCr}$ levels when inhibition of renal transporter(s) is suspected is provided in Fig. 4. First, GFR should be determined with an alternative method (e.g., measurement of serum levels of cystatin $C$ ) to rule out renal impairment as a cause for the creatinine increase. Serum cystatin $C$ is a more accurate biomarker for GFR estimation because it is filtered in the glomeruli, but not secreted by renal transporters [55]. Other methods such as inulin [63] or radioisotopes also are available, but are impractical 
clinically as these methods can be costly and time-consuming and may delay clinical intervention. If the GFR measured with an alternative method remains suppressed, potential renal injury can be investigated with various biomarkers (see Section 7). If GFR is not affected, then OCT2 or MATE inhibition can be explored with an in vitro study. An $\mathrm{IC}_{50}$ in the range of clinically relevant concentrations would support inhibition of renal transporters as the mechanism for the $\mathrm{sCr}$ increase. Other mechanisms such as changes in sCr production (e.g., diet, disease status) would need to be explored if the $\mathrm{sCr}$ increase is not explained by inhibition of renal transporters.

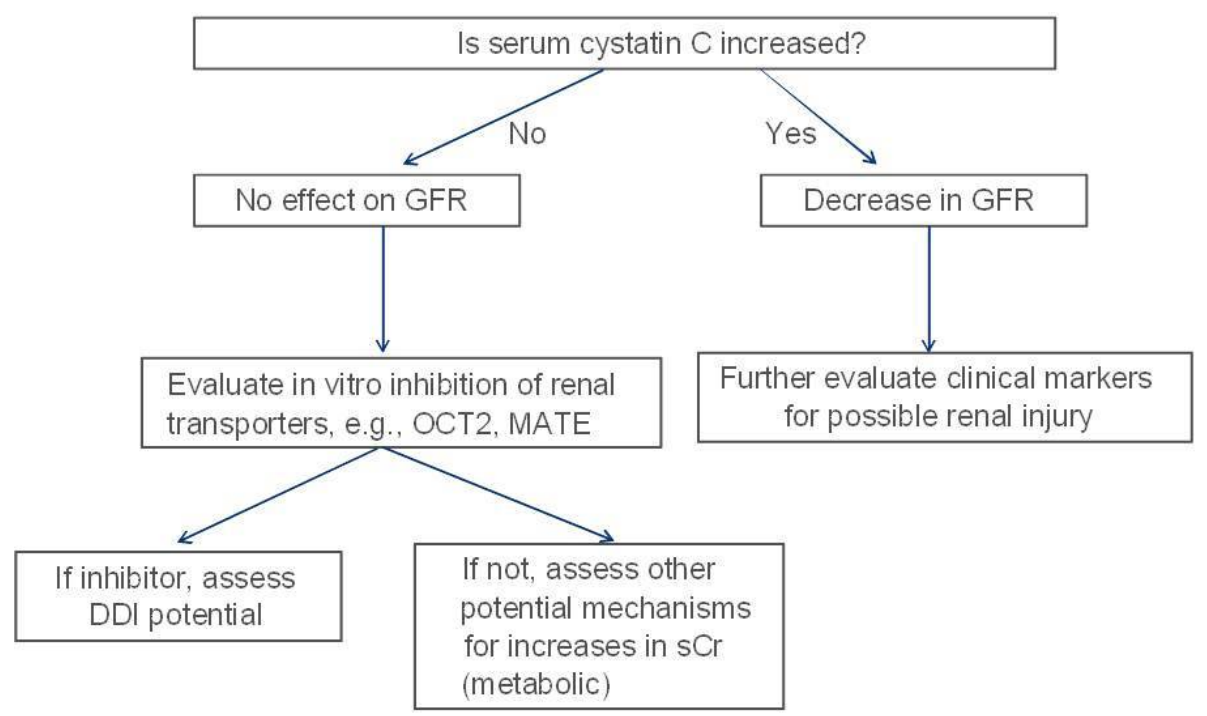

Figure 4. Strategy to investigate involvement of renal transporters in $\mathrm{s} C r$ changes.

Compound A was investigated with the described strategy (Fig. 4). Although sCr was increased, GFR was not affected when calculated with serum cystatin C. Compound A was then tested for OCT2 inhibition and shown to inhibit metformin uptake into $\mathrm{CHO}$ cells expressing OCT2 in a concentration-dependent manner (Fig. 5). Concentrations of Compound A were similar between the in vitro inhibition profile and human plasma concentrations where sCr increases were observed. Based on these data, Compound A was considered to increase sCr levels by inhibiting tubular secretion of creatinine via OCT2.

Similar to OCT2, elevation of sCr by a drug can also occur with the inhibition of MATE transporters. For example, pyrimethamine, a potent inhibitor of MATE transporters and a weak inhibitor of OCT2 [64], increased sCr within $28 \mathrm{~h}$ from $81+/-14$ to $102+/-16 \mu \mathrm{M}(\mathrm{P}=$ 0.002) in the healthy volunteers [65]. Therefore, inhibition of MATE transporters should also be considered to be a potential mechanism when increased levels of $\mathrm{sCr}$ are clinicallyassociated with drug administration. 


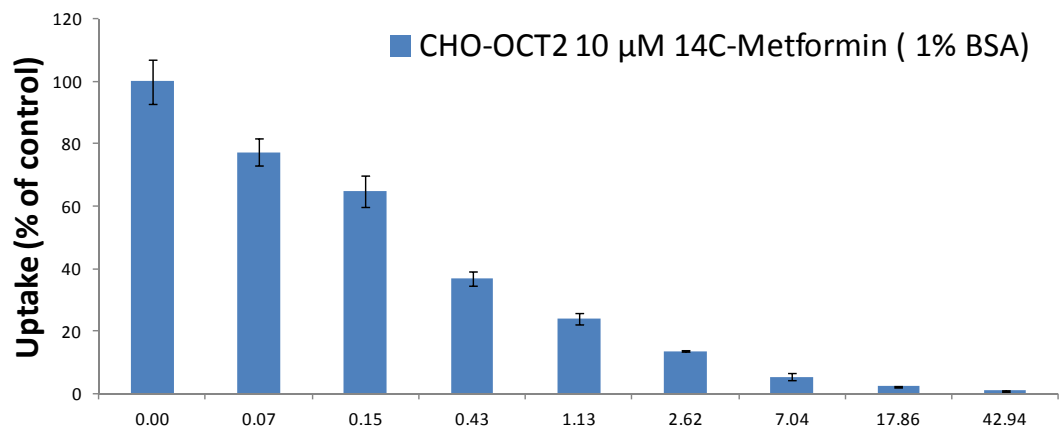

Concentration of Compound $\mathrm{A}(\mu \mathrm{M})$

Figure 5. Inhibition of metformin uptake into $\mathrm{CHO}$ cells expressing OCT2 by Compound A. With $\mathrm{CHO}$ cells, stably transfected with cDNA encoding for OCT2, transport of a prototypical substrate of OCT2, metformin (10 $\mu \mathrm{M}, 1 \mathrm{~min})$ was determined in the presence and absence of various concentrations of Compound $A$.

\section{Importance of biomarkers in renal safety assessment}

While the aforementioned examples in this chapter show that concentrations of drug and/or metabolites in tissues provide greater predictivity for toxicity compared to plasma, routine tissue sampling is not generally feasible in clinical safety assessments. Biomarkers are important tools in renal safety assessment because they can provide early and non-invasive indication of compound-induced toxicities. Regulatory agencies (i.e., United States Food \& Drug Administration, FDA; European Medicines Agency, EMA and/or Japanese Pharmaceuticals \& Medical Devices Agency, PMDA) have recognized the need for novel, qualified, translational renal biomarkers [66-68]. Traditional renal biomarkers, $\mathrm{sCr}$ and $\mathrm{BUN}$, used in both preclinical and clinical settings lack both specificity and sensitivity. For example, increases in $\mathrm{sCr}$ and BUN levels may reflect alteration in GFR that can occur with or without renal tubular pathology and increases in $\mathrm{sCr}$ and BUN are measureable 2-3 days after significant loss of renal function because the kidney has a huge functional reserve [69, 70]. Increased sCr may be predictive of kidney injury only when nearly half of the functional nephron capacity has been lost and the kidneys are unable to regulate fluid and electrolyte homeostasis [71]. sCr may also be elevated due to physiologic states unrelated to compound-induced nephrotoxicity such as dehydration and muscle damage [68, 72].

To date, eight urinary rat renal biomarkers have been qualified by the Critical Path Institute's Predictive Safety Testing Consortium (PSTC), Nephrotoxicity Working Group [66, 67] and the International Life Sciences Institute-Health and Environmental Safety Institute (ILSI-HESI), Biomarkers of Nephrotoxicity Project Group [68] for monitoring compound-induced, progressive renal injury in rats. The qualified rat renal biomarkers include urinary markers: kidney injury molecule-1 (KIM-1), albumin, total protein, B2-microalbumin, cystatin C, clusterin, trefoil factor-3 (TFF-3) and renal papillary antigen-1 (RPA-1). These novel biomarkers are 
highly sensitive, specific (show differential expression patterns within nephron segments), and add to the diagnostic values of sCr and BUN.

The utility of these qualified rat urinary renal biomarkers include monitoring renal function, tissue injury response and tissue leakage [72]. Functional renal biomarkers are used for monitoring changes in renal physiology, GFR and/or tubular reabsorption and include urinary total protein [73-77], albumin [75, 78, 79], ß2-microalbumin [80], and cystatin C. High levels of proteins in urine (proteinuria) indicate progressive loss of renal function and alterations of the glomerular filtration barrier such as damage to the glomerular podocytes or leakage of plasma proteins into the filtrate. Urinary albumin is synthesized in the liver, circulates in systemic blood vessels, and is a major high molecular weight serum protein larger than the pores of the glomerular filter. Albumin is normally filtered and absorbed by proximal tubule epithelium, degraded, and reutilized or excreted into the urine; therefore, the appearance of albumin in urine represents injury to the glomerular basement membrane [72]. Glomerular injury with subsequent impairment of tubular reabsorption may be detected by urinary levels of $B 2$-microalbumin and cystatin C; which appear to be more reliable than traditional renal biomarkers, $\mathrm{sCr}$ and $\mathrm{BUN}$ [67]. The gene for cystatin $C$ is expressed in all nucleated cells and bears the characteristics of a housekeeping gene; therefore, cystatin $C$ production rate is assumed to remain constant, a characteristic which lends to its utility in the clinic as an endogenous marker of GFR [80]. B2microalbumin is produced by mononulear cells which limits use as a GFR marker.

Urinary total protein, urinary albumin, urinary $\$ 2$-microalbumin and urinary cystatin $\mathrm{C}$ are qualified for use in GLP rat studies to assess potential glomerular changes and/or impaired tubular reabsorption [67]. When compound-induced tubular injury or glomerular alterations have been identified in rat studies, urinary total protein, urinary albumin, urinary $\beta 2-$ microglobulin and urinary cystatin $\mathrm{C}$ can be used as bridging biomarkers to monitor kidney safety in clinical settings.

Renal tissue injury response biomarkers that have been qualified for monitoring compoundinduced renal injury in the rat include urinary KIM-1, urinary clusterin, urinary RPA-1 and urinary TFF-3. Urinary KIM-1, also referred to as T-cell immunoglobulin mucin-1 (TIM-1) or hepatitis A virus cellular receptor-1 (HAVCR-1) is expressed primarily but not exclusively in proximal tubular epithelial cells and lymphocytes [81, 82]. KIM-1 mRNA and subsequently KIM-1 protein is expressed during de-differentiation of proximal tubular epithelial cells. KIM-1 has been reported to function as a receptor in the phagocytosis of apoptotic tubule epithelial cells [82]. When KIM-1 protein is cleaved, the ectodomain is shed into the urine and is stable at room temperature for several hours. KIM-1 has specificity and sensitivity for use as a urinary biomarker to monitor compound-induced proximal tubular injury in rats. Similar KIM-1 characteristics observed in the rat have been demonstrated in humans; and the cleaved ectodomain of KIM-1 can be detected in the urine of patients with acute tubular necrosis; therefore, urinary KIM-1 is also considered qualified as a clinical bridging biomarker to monitor kidney safety in clinical studies on a "case-by-case" basis following the identification of tubular injury in rats [82]. 
Early detection and sensitivity of urinary KIM-1 as a biomarker of renal tubular injury were demonstrated with a model of cisplatin-induced acute kidney injury (AKI) in male Sprague Dawley rats treated for $1,3,5,7$, or 14 days at $1 \mathrm{mg} / \mathrm{kg} /$ day [83]. As early as 1 day after cisplatin treatment, positive KIM-1 immunostaining, observed in the outer medulla of the kidney, indicated the onset of proximal tubular injury in the absence of functional changes. After 3 days of treatment, KIM-1 protein levels in urine increased more than 20-fold concurrently with tubular basophilia. After 5 days, sCr and BUN levels were elevated concurrently with tubular degeneration. Cisplatin-induced increases in urinary and renal KIM-1 protein levels were detected prior to changes in BUN, demonstrating the sensitivity of KIM-1 as a diagnostic tool for detection of compound-induced proximal tubular injury in rats.

In another study in male Beagle dogs, KIM-1 was identified as a renal tissue injury response marker (author's unpublished data). Animals were intravenously administered cisplatin [0.75 $\mathrm{mg} / \mathrm{kg} /$ day for up to 5 days) and humanely euthanized when $\mathrm{sCr}$ levels were $\geq 1.9 \mathrm{mg} / \mathrm{dL}$, indicating significant loss of GFR. AKI was histologically characterized by tubule dilatation, vacuolization, degeneration, regeneration, and interstitial inflammation. Increased sCr was not observed until approximately day 16 (Fig. 6], while increased urinary KIM-1 mRNA levels were detected as early as Day 2 and were highly predictive of cisplatin-induced renal tissue injury. KIM-1 protein expression was detected in the injured proximal tubular epithelial cells (degenerated, vacuolized and dilated tubules) or regenerated proximal tubular epithelial cells (tubular basophilia), primarily in the S2 segment correlated with histomorphologic changes (Fig. 7). Neither urinary KIM-1 mRNA by quantitative polymerase chain reaction analysis nor renal KIM-1 protein expression with immunostaining in canines with compound-induced AKI has been previously reported.

Another renal injury biomarker, clusterin, exists as a secreted isoform or a nuclear isoform, although only the $80 \mathrm{kDa}$ glycosylated secreted isoform is constitutively expressed during early stages of renal development and later in response to injury to proximal and distal tubules, papillae, glomeruli, and collecting ducts [72, 81, 84, 85]. Secreted clusterin is believed to be anti-apoptotic, and involved in lipid recycling, cell aggregation and cell attachment. Urinary clusterin levels correlate with the severity of tubular damage [84]. In male Wistar rats, clusterin mRNA was markedly induced and immunostaining demonstrated clusterin primarily in tubules in the cortex and medulla following administration of puromycin aminonucleoside (15 mg/100 g body weight, subcutaneously). Clusterin may differentiate between glomerular and tubular injuries [84]. In a model of cisplatin-induced AKI in male Sprague Dawley rats, urinary clusterin measurements were detected prior to changes in BUN [83]. Positive clusterin immunostaining accurately correlated with the histopathologic findings. Urinary clusterin has not been approved for clinical use [82].

Induction of RPA-1 expression correlates with immunoreactivity of inducible nitric oxide synthase (iNOS) and nitrotyrosine. Thus, RPA-1 is believed to be increased in the cytoplasm of intact cells of the collecting duct epithelium and proximal tubule epithelium following compound-induced injury to nephron segments as a result of iNOS-dependent signal transduction pathways $[72,86]$. Rat renal RPA-1 is highly expressed in the epithelial cells in medullary (papilla) and cortical collecting ducts and in the medullary loop of Henle. In the rat, 
A

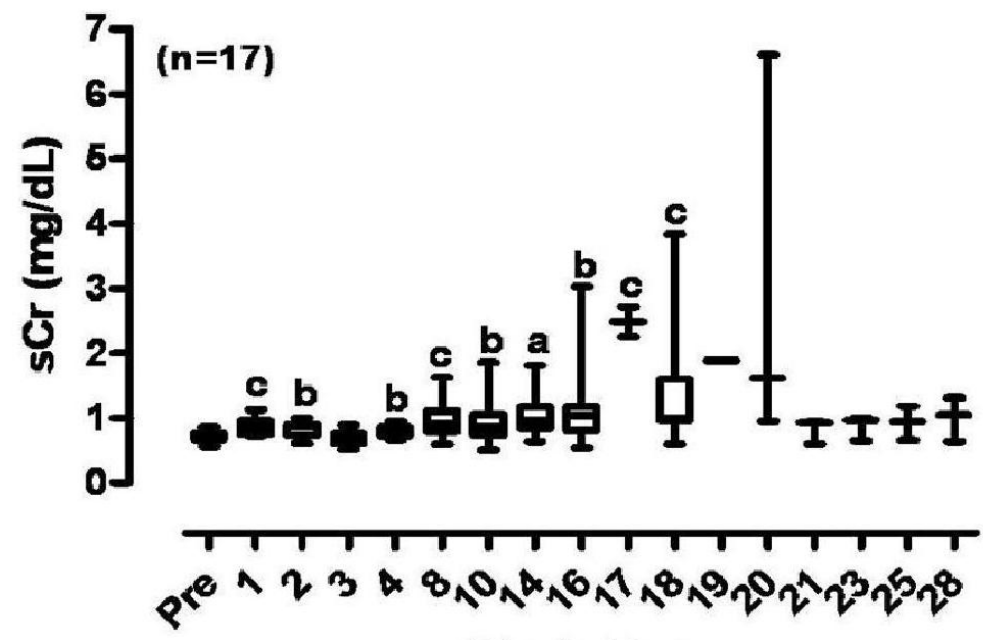

Study Day

B

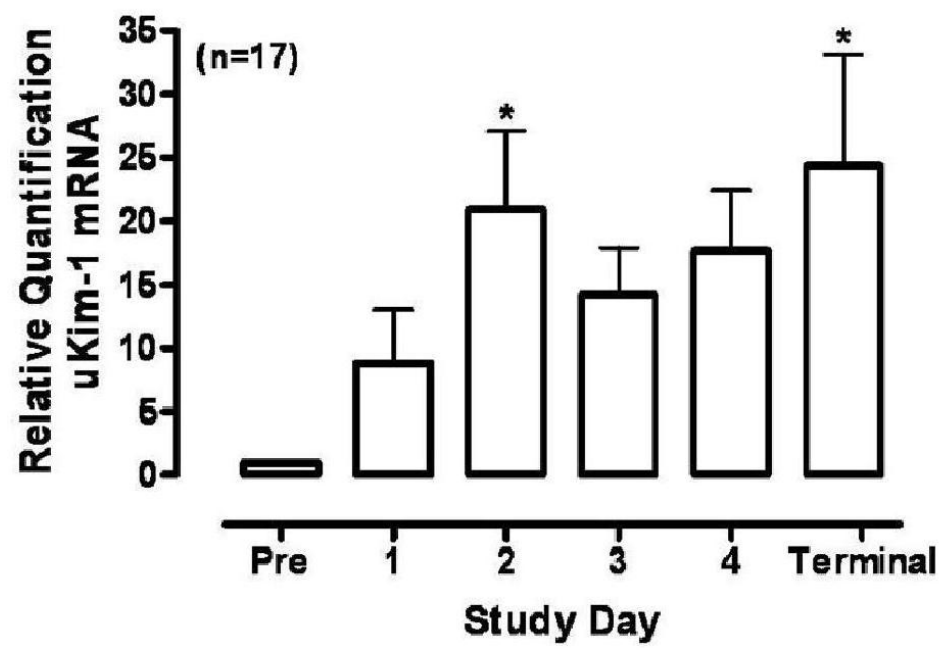

Figure 6. $\mathrm{s} C r$ and urinary $\mathrm{KIM}-1$ (uKIM-1] mRNA measurements in dogs with cisplatin-induced AKI. (A) sCr increased significantly in one dog on day 16. (B) Relative quantification of UKIM-1 mRNA levels in dogs with cisplatin-induced AKI. Data are means \pm SEM; $a$ indicates $P<0.001$, $b$ indicates $P<0.01$, and $c$ and * indicate $P<0.05$ relative to predose (Pre) values. 


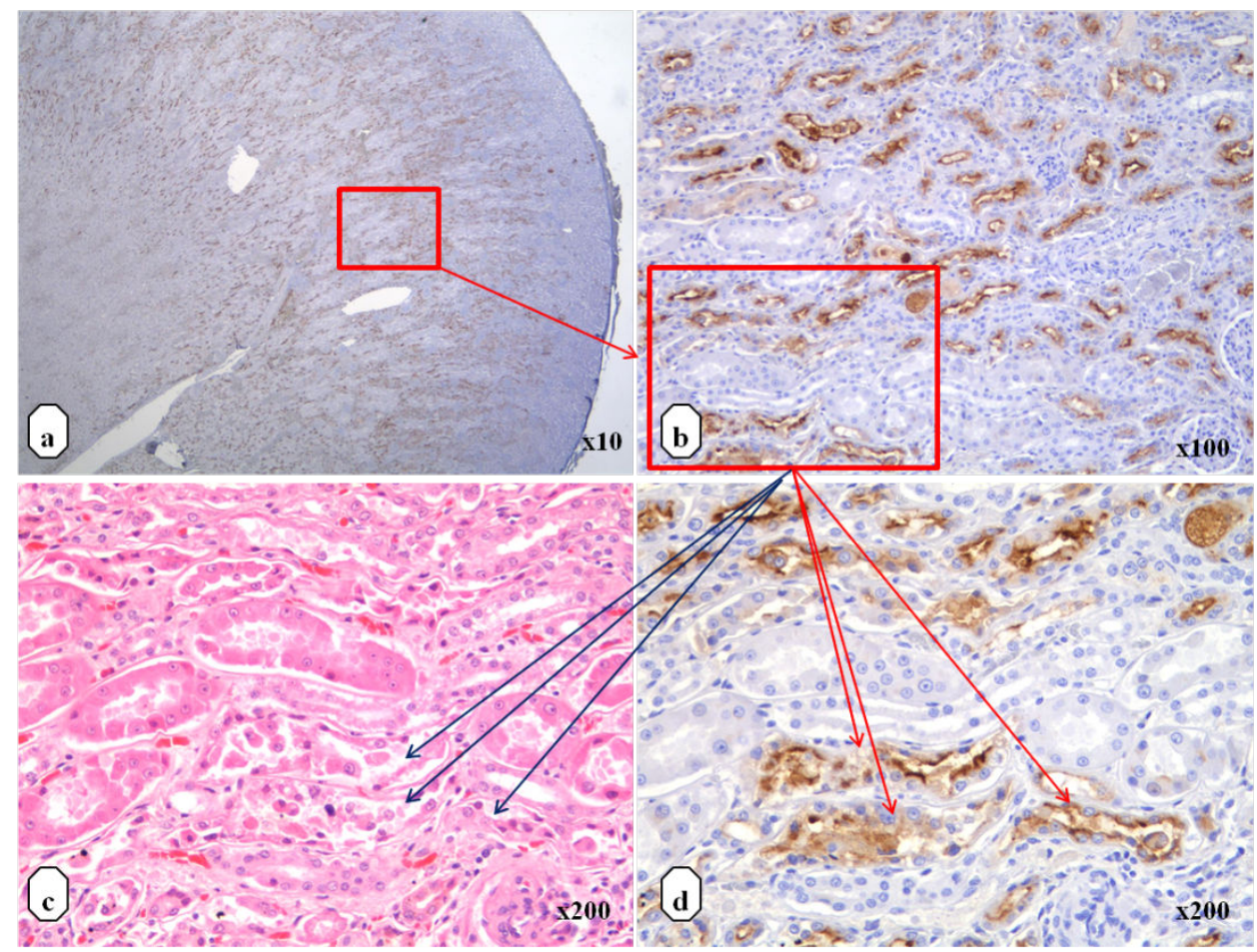

Figure 7. Representative hematoxylin and eosin-staining in a cisplatin-treated dog indicating tubular degeneration in proximal tubules (c); representative cytoplasmic renal KIM-1 immunostaining in $\$ 2$ segment proximal tubular epithelial cells ( $a, b$ and $d)$.

urinary RPA-1 is the qualified diagnostic marker of choice for monitoring compound-induced progressive renal papillary necrosis [50] and recovery [72]. TFF-3 is expressed in tubules of the outer stripe of the outer medulla; urinary TFF3 protein levels are markedly reduced in response to renal tubular injury [79]; however, TFF-3 may not outperform BUN and/or sCr to detect kidney injury in rats [79]. Neither urinary RPA-1 nor urinary TFF-3 [79] has been qualified for clinical use to date.

Tissue leakage markers: glutathione-S-transferase alpha ( $\alpha$-GST), glutathione-S-transferase$\mathrm{mu}$ (mu-GST/GSTYb1), and N-acetyl- $\beta$-D-glucosaminidase (NAG) are released from cells upon structural damage to proximal tubular epithelium (rat $\alpha$-GST) and distal tubular epithelium (rat mu-GST) and reflect primarily tubular cell necrosis in various animal models $[83,87,88]$ and humans [89] where compound induced kidney injury was evident. Yet, $\alpha$-GST, mu-GST, and NAG have not been qualified; and their translational characteristics have not been well defined to date.

In conclusion, the importance of biomarkers in renal safety assessment have been described with emphasis on those biomarkers that have been qualified in rats and on a case-by-case basis 
in the clinical setting [67]. Other potentially translational biomarkers of kidney injury have been reported and are under consideration for qualification [90-92]. In addition, biomarkers specific to a condition or disease are available. For example, erythropoietin (EPO) which is produced primarily by fibroblast-like cortical interstitial cells in the kidney and functions to prevent apoptosis of early erythroid precursor cells can be used as a biomarker for various conditions of anemia [93], secondary forms of polycythemia [94], and abuse of erythropoiesis-stimulating agents by athletes [95]. Another example is ferritin, a ubiquitous intracellular protein that functions to store iron in a non-toxic form [96]. Serum ferritin levels correlate with total body iron stores and is often used along with other iron tests as a biomarker for determination of endogenous iron stores to aid diagnosis of disease including but not limited to iron deficiency anemia and acute renal failure [97] in patients with nephrohotic proteinuria likely due to non-specific hepatic protein synthesis to compensate for loss of iron-binding transferrin [98].

\section{Conclusions}

Increased understanding of the effect of renal transporters on the distribution of a drug will enhance safety assessment. Limiting the accumulation and/or distribution of a compound to the kidney through selective interaction with renal transporters will potentially identify safer drugs. Renal transporters also can be exploited as potential targets for therapeutic agents by affecting the disposition of endogenous substrates. In the case of $\mathrm{sCr}$, potential inhibition of renal transporters can limit its utility as a safety biomarker. Whereas data are available for the relationship between 8 qualified biomarkers that outperform $\mathrm{sCr}$ and/or BUN in monitoring compound-induced renal injury in rats, the translation from rats to humans is limited by the availability of qualified human biomarkers. Efforts are in progress to further assess the translatability of urinary biomarkers in higher species including canines, non-human primates and humans.

\section{Acknowledgements}

We would like to thank Maarten Huisman for his contribution to OCT2 inhibition study. The support of dog renal biomarker studies from Marciano Sablad, Antonio Guy, Jennifer Vegas, Lynn Varacallo, Jing Ying Ma, Anton Bittner, Jingin Gao, and Manisha Sonee is greatly appreciated. We would also like to thank Shannon Dallas, Manisha Sonee, and Sandra Snook for their thorough review of this chapter

\section{Author details}

P.D. Ward, D. La and J.E. McDuffie

Janssen Research \& Development, L.L.C, USA 


\section{References}

[1] Ward P. Importance of drug transporters in pharmacokinetics and drug safety. Toxicol Mech Methods. 2008;18(1):1-10.

[2] Dallas S, Ward P. Drug Transporters and ADME. In: Swarbrick J, editor. Encyclopedia of Pharmaceutical Technology. 4th ed. New York: Informa Healthcare; in press.

[3] Jones PM, George AM. The ABC transporter structure and mechanism: perspectives on recent research. Cell Mol Life Sci. 2004 Mar;61(6):682-99.

[4] Lin JH. Drug-drug interaction mediated by inhibition and induction of P-glycoprotein. Adv Drug Deliv Rev. 2003 Jan 21;55(1):53-81.

[5] Lin JH, Yamazaki M. Role of P-glycoprotein in pharmacokinetics: clinical implications. Clin Pharmacokinet. 2003;42(1):59-98.

[6] Borst P, Evers R, Kool M, Wijnholds J. A family of drug transporters: the multidrug resistance-associated proteins. J Natl Cancer Inst. 2000 Aug 16;92(16):1295-302.

[7] Hediger MA, Romero MF, Peng JB, Rolfs A, Takanaga H, Bruford EA. The ABCs of solute carriers: physiological, pathological and therapeutic implications of human membrane transport proteinsIntroduction. Pflugers Arch. 2004 Feb;447(5):465-8.

[8] Giacomini KM, Sugiyama Y. Membrane Transporters and Drug Response. In: Brunton LL, editor. Goodman \& Gilman's The Pharmacological Basis of Therapeutics. 12th ed: McGraw-Hill; 2011.

[9] Anzai N, Endou H. Drug transport in the kidney. In: You G, Morris M, editors. Drug transporters, molecular characterization and Role in Drug Disposition: John Wiley and Sons; 2007.

[10] Hilgendorf C, Ahlin G, Seithel A, Artursson P, Ungell AL, Karlsson J. Expression of thirty-six drug transporter genes in human intestine, liver, kidney, and organotypic cell lines. Drug Metab Dispos. 2007 Aug;35(8):1333-40.

[11] Moriyama Y, Hiasa M, Matsumoto T, Omote H. Multidrug and toxic compound extrusion (MATE)-type proteins as anchor transporters for the excretion of metabolic waste products and xenobiotics. Xenobiotica. 2008 Jul;38(7-8):1107-18.

[12] Damme K, Nies AT, Schaeffeler E, Schwab M. Mammalian MATE (SLC47A) transport proteins: impact on efflux of endogenous substrates and xenobiotics. Drug Metab Rev. 2011 Nov;43(4):499-523.

[13] Nozaki Y, Kusuhara H, Kondo T, Iwaki M, Shiroyanagi Y, Nakayama H, et al. Species difference in the inhibitory effect of nonsteroidal anti-inflammatory drugs on the uptake of methotrexate by human kidney slices. J Pharmacol Exp Ther. 2007 Sep; 322(3):1162-70. 
[14] Uwai $Y$, Saito H, Inui K. Interaction between methotrexate and nonsteroidal anti-inflammatory drugs in organic anion transporter. Eur J Pharmacol. 2000 Dec 1;409(1): $31-6$.

[15] Fujita T, Urban TJ, Leabman MK, Fujita K, Giacomini KM. Transport of drugs in the kidney by the human organic cation transporter, OCT2 and its genetic variants. J Pharm Sci. 2006 Jan;95(1):25-36.

[16] Koepsell H, Lips K, Volk C. Polyspecific organic cation transporters: structure, function, physiological roles, and biopharmaceutical implications. Pharm Res. 2007 Jul; 24(7):1227-51.

[17] Muller F, Fromm MF. Transporter-mediated drug-drug interactions. Pharmacogenomics. 2011 Jul;12(7):1017-37.

[18] Van Aubel RA, Masereeuw R, Russel FG. Molecular pharmacology of renal organic anion transporters. Am J Physiol Renal Physiol. 2000 Aug;279(2):F216-32.

[19] Rizwan AN, Burckhardt G. Organic anion transporters of the SLC22 family: biopharmaceutical, physiological, and pathological roles. Pharm Res. 2007 Mar;24(3):450-70.

[20] Weiss J, Theile D, Ketabi-Kiyanvash N, Lindenmaier H, Haefeli WE. Inhibition of MRP1/ABCC1, MRP2/ABCC2, and MRP3/ABCC3 by nucleoside, nucleotide, and non-nucleoside reverse transcriptase inhibitors. Drug Metab Dispos. 2007 Mar;35(3): 340-4.

[21] Marchetti S, Mazzanti R, Beijnen JH, Schellens JH. Concise review: Clinical relevance of drug drug and herb drug interactions mediated by the ABC transporter ABCB1 (MDR1, P-glycoprotein). Oncologist. 2007 Aug;12(8):927-41.

[22] Cui Y, Konig J, Buchholz JK, Spring H, Leier I, Keppler D. Drug resistance and ATPdependent conjugate transport mediated by the apical multidrug resistance protein, MRP2, permanently expressed in human and canine cells. Mol Pharmacol. 1999 May; 55(5):929-37.

[23] Suzuki H, Sugiyama Y. Excretion of GSSG and glutathione conjugates mediated by MRP1 and cMOAT/MRP2. Semin Liver Dis. 1998;18(4):359-76.

[24] Reid G, Wielinga P, Zelcer N, De Haas M, Van Deemter L, Wijnholds J, et al. Characterization of the transport of nucleoside analog drugs by the human multidrug resistance proteins MRP4 and MRP5. Mol Pharmacol. 2003 May;63(5):1094-103.

[25] Reid G, Wielinga P, Zelcer N, van der Heijden I, Kuil A, de Haas M, et al. The human multidrug resistance protein MRP4 functions as a prostaglandin efflux transporter and is inhibited by nonsteroidal antiinflammatory drugs. Proc Natl Acad Sci U S A. 2003 Aug 5;100(16):9244-9. 
[26] Dixit R, Ward P. Use of Classical Pharmacokinetic Evaluations in Drug Development and Safety Assessment. In: Lipscomb JC, Ohanian EV, editors. Toxicokinetics and Risk Assessment. New York, NY: Informa Healthcare USA Inc.; 2007. p. 95-122.

[27] Ward PD. Toxicokinetics and Organ-Specific Toxicity. In: Acree W, editor. Toxicity and Drug Testing: Intech; 2012.

[28] Tanihara Y, Masuda S, Katsura T, Inui K. Protective effect of concomitant administration of imatinib on cisplatin-induced nephrotoxicity focusing on renal organic cation transporter OCT2. Biochem Pharmacol. 2009 Nov 1;78(9):1263-71.

[29] Anzai N, Endou H. Renal drug transporters and nephrotoxicity. AATEX. 2007;14(Special Issue):447-52.

[30] Cihlar T, Lin DC, Pritchard JB, Fuller MD, Mendel DB, Sweet DH. The antiviral nucleotide analogs cidofovir and adefovir are novel substrates for human and rat renal organic anion transporter 1. Mol Pharmacol. 1999 Sep;56(3):570-80.

[31] Cundy KC. Clinical pharmacokinetics of the antiviral nucleotide analogues cidofovir and adefovir. Clin Pharmacokinet. 1999 Feb;36(2):127-43.

[32] Uwai Y, Ida H, Tsuji Y, Katsura T, Inui K. Renal transport of adefovir, cidofovir, and tenofovir by SLC22A family members (hOAT1, hOAT3, and hOCT2). Pharm Res. 2007 Apr;24(4):811-5.

[33] Naesens L, Balzarini J, De Clercq E. Pharmacokinetics in mice of the anti-retrovirus agent 9-(2-phosphonylmethoxyethyl)adenine. Drug Metab Dispos. 1992 Sep-Oct; 20(5):747-52.

[34] Roy CJ, Baker R, Washburn K, Bray M. Aerosolized cidofovir is retained in the respiratory tract and protects mice against intranasal cowpox virus challenge. Antimicrob Agents Chemother. 2003 Sep;47(9):2933-7.

[35] Gallant JE, Parish MA, Keruly JC, Moore RD. Changes in renal function associated with tenofovir disoproxil fumarate treatment, compared with nucleoside reversetranscriptase inhibitor treatment. Clin Infect Dis. 2005 Apr 15;40(8):1194-8.

[36] Roling J, Schmid H, Fischereder M, Draenert R, Goebel FD. HIV-associated renal diseases and highly active antiretroviral therapy-induced nephropathy. Clin Infect Dis. 2006 May 15;42(10):1488-95.

[37] Ho ES, Lin DC, Mendel DB, Cihlar T. Cytotoxicity of antiviral nucleotides adefovir and cidofovir is induced by the expression of human renal organic anion transporter 1. J Am Soc Nephrol. 2000 Mar;11(3):383-93.

[38] Cihlar T, Ho ES, Lin DC, Mulato AS. Human renal organic anion transporter 1 (hOAT1) and its role in the nephrotoxicity of antiviral nucleotide analogs. Nucleosides Nucleotides Nucleic Acids. 2001 Apr-Jul;20(4-7):641-8. 
[39] Mulato AS, Ho ES, Cihlar T. Nonsteroidal anti-inflammatory drugs efficiently reduce the transport and cytotoxicity of adefovir mediated by the human renal organic anion transporter 1. J Pharmacol Exp Ther. 2000 Oct;295(1):10-5.

[40] Peyriere H, Reynes J, Rouanet I, Daniel N, de Boever CM, Mauboussin JM, et al. Renal tubular dysfunction associated with tenofovir therapy: report of 7 cases. J Acquir Immune Defic Syndr. 2004 Mar 1;35(3):269-73.

[41] Imaoka T, Kusuhara H, Adachi M, Schuetz JD, Takeuchi K, Sugiyama Y. Functional involvement of multidrug resistance-associated protein 4 (MRP4/ABCC4) in the renal elimination of the antiviral drugs adefovir and tenofovir. Mol Pharmacol. 2007 Feb; 71(2):619-27.

[42] Madeddu G, Bonfanti P, De Socio GV, Carradori S, Grosso C, Marconi P, et al. Tenofovir renal safety in HIV-infected patients: results from the SCOLTA Project. Biomed Pharmacother. 2008 Jan;62(1):6-11.

[43] Borst P, Balzarini J, Ono N, Reid G, de Vries H, Wielinga P, et al. The potential impact of drug transporters on nucleoside-analog-based antiviral chemotherapy. Antiviral Res. 2004 Apr;62(1):1-7.

[44] Yokoo S, Yonezawa A, Masuda S, Fukatsu A, Katsura T, Inui K. Differential contribution of organic cation transporters, OCT2 and MATE1, in platinum agent-induced nephrotoxicity. Biochem Pharmacol. 2007 Aug 1;74(3):477-87.

[45] Burger H, Loos WJ, Eechoute K, Verweij J, Mathijssen RH, Wiemer EA. Drug transporters of platinum-based anticancer agents and their clinical significance. Drug Resist Updat. 2011 Feb;14(1):22-34.

[46] Pfister T, Atzpodien E, Bauss F. The renal effects of minimally nephrotoxic doses of ibandronate and zoledronate following single and intermittent intravenous administration in rats. Toxicology. 2003 Sep 30;191(2-3):159-67.

[47] Bauss F, Russell RG. Ibandronate in osteoporosis: preclinical data and rationale for intermittent dosing. Osteoporos Int. 2004 Jun;15(6):423-33.

[48] Body JJ, Pfister T, Bauss F. Preclinical perspectives on bisphosphonate renal safety. Oncologist. 2005;10 Suppl 1:3-7.

[49] Lin JH. Bisphosphonates: a review of their pharmacokinetic properties. Bone. 1996 Feb;18(2):75-85.

[50] Anzai N, Kanai Y, Endou H. Organic anion transporter family: current knowledge. J Pharmacol Sci. 2006;100(5):411-26.

[51] Caulfield MJ, Munroe PB, O'Neill D, Witkowska K, Charchar FJ, Doblado M, et al. SLC2A9 is a high-capacity urate transporter in humans. PLoS Med. 2008 Oct 7;5(10):e197. 
[52] Wood IS, Trayhurn P. Glucose transporters (GLUT and SGLT): expanded families of sugar transport proteins. Br J Nutr. 2003 Jan;89(1):3-9.

[53] Santer R, Kinner M, Lassen CL, Schneppenheim R, Eggert P, Bald M, et al. Molecular analysis of the SGLT2 gene in patients with renal glucosuria. J Am Soc Nephrol. 2003 Nov;14(11):2873-82.

[54] Chao EC. A paradigm shift in diabetes therapy--dapagliflozin and other SGLT2 inhibitors. Discov Med. 2011 Mar;11(58):255-63.

[55] Dharnidharka VR, Kwon C, Stevens G. Serum cystatin C is superior to serum creatinine as a marker of kidney function: a meta-analysis. Am J Kidney Dis. 2002 Aug; 40(2):221-6.

[56] Roos JF, Doust J, Tett SE, Kirkpatrick CM. Diagnostic accuracy of cystatin C compared to serum creatinine for the estimation of renal dysfunction in adults and children--a meta-analysis. Clin Biochem. 2007 Mar;40(5-6):383-91.

[57] Breyer MD, Qi Z. Better nephrology for mice--and man. Kidney Int. 2010 Mar;77(6): 487-9.

[58] Imamura Y, Murayama N, Okudaira N, Kurihara A, Okazaki O, Izumi T, et al. Prediction of fluoroquinolone-induced elevation in serum creatinine levels: a case of drug-endogenous substance interaction involving the inhibition of renal secretion. Clin Pharmacol Ther. 2011 Jan;89(1):81-8.

[59] Sarapa N, Wickremasingha P, Ge N, Weitzman R, Fuellhart M, Yen C, et al. Lack of effect of DX-619, a novel des-fluoro(6)-quinolone, on glomerular filtration rate measured by serum clearance of cold iohexol. Antimicrob Agents Chemother. 2007 Jun; 51(6):1912-7.

[60] Tett SE, Kirkpatrick CM, Gross AS, McLachlan AJ. Principles and clinical application of assessing alterations in renal elimination pathways. Clin Pharmacokinet. 2003;42(14):1193-211.

[61] Kastrup J, Petersen P, Bartram R, Hansen JM. The effect of trimethoprim on serum creatinine. Br J Urol. 1985 Jun;57(3):265-8.

[62] van Acker BA, Koomen GC, Koopman MG, de Waart DR, Arisz L. Creatinine clearance during cimetidine administration for measurement of glomerular filtration rate. Lancet. 1992 Nov 28;340(8831):1326-9.

[63] Nakata J, Ohsawa I, Onda K, Tanimoto M, Kusaba G, Takeda Y, et al. Risk of Overestimation of Kidney Function Using GFR-Estimating Equations in Patients with Low Inulin Clearance. J Clin Lab Anal. 2012;26(4):248-53.

[64] Ito S, Kusuhara H, Kuroiwa Y, Wu C, Moriyama Y, Inoue K, et al. Potent and specific inhibition of mMate1-mediated efflux of type I organic cations in the liver and kidney by pyrimethamine. J Pharmacol Exp Ther. 2010 Apr;333(1):341-50. 
[65] Opravil M, Keusch G, Luthy R. Pyrimethamine inhibits renal secretion of creatinine. Antimicrob Agents Chemother. 1993 May;37(5):1056-60.

[66] Dennis E, Walker E, Baker A, Lundstrom G, King N, Short K. Predictive Safety Testing Consortium. http://c-pathorg/pstccfm\#Milestones.

[67] Dieterle F, Sistare F, Goodsaid F, Papaluca M, Ozer JS, Webb CP, et al. Renal biomarker qualification submission: a dialog between the FDA-EMEA and Predictive Safety Testing Consortium. Nat Biotechnol. 2010 May;28(5):455-62.

[68] Harpur E, Ennulat D, Hoffman D, Betton G, Gautier JC, Riefke B, et al. Biological qualification of biomarkers of chemical-induced renal toxicity in two strains of male rat. Toxicol Sci. 2011 Aug;122(2):235-52.

[69] Andreoli CM, Andreoli MT, Kloek CE, Ahuero AE, Vavvas D, Durand ML. Low rate of endophthalmitis in a large series of open globe injuries. Am J Ophthalmol. 2009 Apr;147(4):601-8 e2.

[70] Gautier JC, Riefke B, Walter J, Kurth P, Mylecraine L, Guilpin V, et al. Evaluation of novel biomarkers of nephrotoxicity in two strains of rat treated with Cisplatin. Toxicol Pathol. 2012 Oct;38(6):943-56.

[71] Bonventre JV, Vaidya VS, Schmouder R, Feig P, Dieterle F. Next-generation biomarkers for detecting kidney toxicity. Nat Biotechnol. 2010 May;28(5):436-40.

[72] Rouse RL, Zhang J, Stewart SR, Rosenzweig BA, Espandiari P, Sadrieh NK. Comparative profile of commercially available urinary biomarkers in preclinical drug-induced kidney injury and recovery in rats. Kidney Int. 2012 Jun;79(11):1186-97.

[73] Guder WG, Hofmann W. Markers for the diagnosis and monitoring of renal tubular lesions. Clin Nephrol. 1992;38 Suppl 1:S3-7.

[74] Herget-Rosenthal S, Poppen D, Husing J, Marggraf G, Pietruck F, Jakob HG, et al. Prognostic value of tubular proteinuria and enzymuria in nonoliguric acute tubular necrosis. Clin Chem. 2004 Mar;50(3):552-8.

[75] Peterson PA, Evrin PE, Berggard I. Differentiation of glomerular, tubular, and normal proteinuria: determinations of urinary excretion of beta-2-macroglobulin, albumin, and total protein. J Clin Invest. 1969 Jul;48(7):1189-98.

[76] Schmid H, Henger A, Cohen CD, Frach K, Grone HJ, Schlondorff D, et al. Gene expression profiles of podocyte-associated molecules as diagnostic markers in acquired proteinuric diseases. J Am Soc Nephrol. 2003 Nov;14(11):2958-66.

[77] Zomas A, Anagnostopoulos N, Dimopoulos MA. Successful treatment of multiple myeloma relapsing after high-dose therapy and autologous transplantation with thalidomide as a single agent. Bone Marrow Transplant. 2000 Jun;25(12):1319-20. 
[78] Greive KA, Nikolic-Paterson DJ, Guimaraes MA, Nikolovski J, Pratt LM, Mu W, et al. Glomerular permselectivity factors are not responsible for the increase in fractional clearance of albumin in rat glomerulonephritis. Am J Pathol. 2001 Sep;159(3):1159-70.

[79] Yu Y, Jin H, Holder D, Ozer JS, Villarreal S, Shughrue P, et al. Urinary biomarkers trefoil factor 3 and albumin enable early detection of kidney tubular injury. Nat Biotechnol. 2010 May;28(5):470-7.

[80] Bokenkamp A, van Wijk JA, Lentze MJ, Stoffel-Wagner B. Effect of corticosteroid therapy on serum cystatin $C$ and beta2-microglobulin concentrations. Clin Chem. 2002 Jul;48(7):1123-6.

[81] Rosenberg ME, Silkensen J. Clusterin and the kidney. Exp Nephrol. 1995 Jan-Feb;3(1): 9-14.

[82] Vaidya VS, Ozer JS, Dieterle F, Collings FB, Ramirez V, Troth S, et al. Kidney injury molecule-1 outperforms traditional biomarkers of kidney injury in preclinical biomarker qualification studies. Nat Biotechnol. 2010 May;28(5):478-85.

[83] Vinken P, Starckx S, Barale-Thomas E, Looszova A, Sonee M, Goeminne N, et al. Tissue Kim-1 and Urinary Clusterin as Early Indicators of Cisplatin-Induced Acute Kidney Injury in Rats. Toxicol Pathol. 2012 May 11.

[84] Correa-Rotter R, Ibarra-Rubio ME, Schwochau G, Cruz C, Silkensen JR, Pedraza-Chaverri J, et al. Induction of clusterin in tubules of nephrotic rats. J Am Soc Nephrol. 1998 Jan;9(1):33-7.

[85] Hidaka S, Kranzlin B, Gretz N, Witzgall R. Urinary clusterin levels in the rat correlate with the severity of tubular damage and may help to differentiate between glomerular and tubular injuries. Cell Tissue Res. 2002 Dec;310(3):289-96.

[86] Zhang J, Goering PL, Espandiari P, Shaw M, Bonventre JV, Vaidya VS, et al. Differences in immunolocalization of Kim-1, RPA-1, and RPA-2 in kidneys of gentamicin-, cisplatin-, and valproic acid-treated rats: potential role of iNOS and nitrotyrosine. Toxicol Pathol. 2009 Aug;37(5):629-43.

[87] Pinches M, Betts C, Bickerton S, Burdett L, Thomas H, Derbyshire N, et al. Evaluation of novel renal biomarkers with a cisplatin model of kidney injury: gender and dosage differences. Toxicol Pathol. 2012 Apr;40(3):522-33.

[88] Sasaki D, Yamada A, Umeno H, Kurihara H, Nakatsuji S, Fujihira S, et al. Comparison of the course of biomarker changes and kidney injury in a rat model of drug-induced acute kidney injury. Biomarkers. 2011 Nov;16(7):553-66.

[89] Westhuyzen J, Endre ZH, Reece G, Reith DM, Saltissi D, Morgan TJ. Measurement of tubular enzymuria facilitates early detection of acute renal impairment in the intensive care unit. Nephrol Dial Transplant. 2003 Mar;18(3):543-51. 
[90] Adiyanti S, Loho T. Acute Kidney Injury (AKI) Biomarker. Acta Medica Indonesiana. 2008;44(3):246-55.

[91] Mehta RL, Kellum JA, Shah SV, Molitoris BA, Ronco C, Warnock DG, et al. Acute Kidney Injury Network: report of an initiative to improve outcomes in acute kidney injury. Crit Care. 2007;11(2):R31.

[92] Xie HG, Wang SK, Cao CC, Harpur E. Qualified kidney biomarkers and their potential significance in drug safety evaluation and prediction. Pharmacol Ther. 2012 Sep 25.

[93] Jelkmann W. Biosimilar recombinant human erythropoietins ("epoetins") and future erythropoiesis-stimulating treatments. Expert Opin Biol Ther. 2012 May;12(5):581-92.

[94] Lasne F, Martin L, Crepin N, de Ceaurriz J. Detection of isoelectric profiles of erythropoietin in urine: differentiation of natural and administered recombinant hormones. Anal Biochem. 2002 Dec 15;311(2):119-26.

[95] Pottgiesser T, Schumacher YO. Biomarker monitoring in sports doping control. Bioanalysis. 2012 Jun;4(10):1245-53.

[96] Goswami B, Tayal D, Mallika V. Ferritin: A multidimensional bio marker. The Internet Journal of Laboratory Medicine 2009;3(2):http://www.ispub.com:80/journal/theinternet-journal-of-laboratory-medicine/volume-3-number-2/ferritin-amultidimensional-bio-marker.html

[97] Mavromatidis K, Fytil C, Kynigopoulou P, Fragia T, Sombolos K. Serum ferritin levels are increased in patients with acute renal failure. Clin Nephrol. 1998 May;49(5): 296-8.

[98] Branten AJ, Swinkels DW, Klasen IS, Wetzels JF. Serum ferritin levels are increased in patients with glomerular diseases and proteinuria. Nephrol Dial Transplant. 2004 Nov;19(11):2754-60. 